\title{
Statistical research on forming of threaded holes in thin plates
}

\author{
P. Krasauskas*, S. Kilikevičius**, R. Česnavičius $* * *$, R. Dundulis**** \\ *Kaunas University of Technology, Studentu 56, 51424 Kaunas, Lithuania, E-mail: povilas.krasauskas@ktu.lt \\ **Kaunas University of Technology, Studentu 56, 51424 Kaunas, Lithuania, E-mail: sigitas.kilikevicius@ktu.lt \\ ***Kaunas University of Technology, Studentu 56, 51424 Kaunas, Lithuania, E-mail: ramunas.cesnavicius@ktu.lt \\ ****Kaunas University of Technology, Studentu 56, 51424 Kaunas, Lithuania, E-mail: romualdas.dundulis@ktu.lt \\ cross $^{\text {ref }}$ http://dx.doi.org/10.5755/j01.mech.22.3.15263
}

\section{Introduction}

Thread machining is widely used operation in various industries; however, it is difficult to tap a hole in thinwalled parts due to the insufficient thickness. Therefore, an additional insert welding operation is required to increase the overall thickness of the wall. In order to avoid this problem, friction drilling along with fluteless tapping can be used. These methods allow to produce threaded holes in thin plates by using special tungsten carbide and HSS tools without cutting edges. Applying this technique, the drilling tool penetrates the material making a hole and simultaneously forming an additional molten flange on the underneath side of the workpiece, which later is tapped using a special tapper. The main stages of forming steps of threaded holes are shown in Fig. 1.
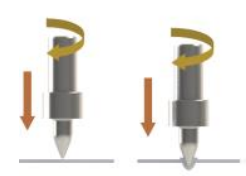

a

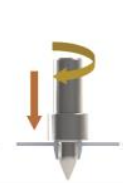

b

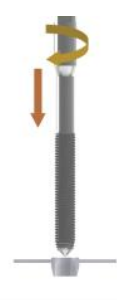

d

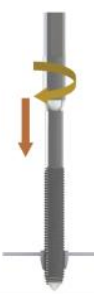

e

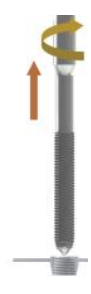

g
Fig. 1 Stages of hole and thread forming in a thin plate: $a$ - initial contact; $b$ - former-tip penetration into the material; c - material flow and hole forming; $\mathrm{d}$ - former withdrawal; e - fast travel of the tapper to the workpiece; $\mathrm{f}$ - extrusion tapping; $\mathrm{g}$ - tapper withdrawal

Scientific works on fluteless manufacturing technologies usually deal with tool wear [1-3], the surface quality of produced holes $[4,5]$ and experimental investigations on the drilling force and moment [6,7]. Paper [8] investigates the effect of fluteless tapping parameters on the responses: torque, hardness, fill rate, and thrust force of the form tapping process.

However, the fluteless tapping process of holes produced by friction drilling was not widely studied and the influence of machining data on the forces and moments which occurs during the process of drilling and tapping is not yet completely investigated.

This paper presents an investigation of the influence of machining data and workpiece thickness on the force and moment of drilling and tapping during friction forming of threaded holes in thin plates along with a multivariable linear regression analysis of the results. A proper adjustment of machining data leads to an increase of forming performance and decrease of tool wear.

\section{Experimental technique of the extrusion drilling and tapping}

The research on the force and moment during drilling and tapping in thin plates was carried out using DC-01 steel sheets with $1.0 \mathrm{~mm}$ and 1.5 in thickness. The mechanical properties of the material are presented in Table 1 .

Table 1

Mechanical material properties

\begin{tabular}{|c|c|c|c|c|}
\hline Material & $\begin{array}{c}\text { Tensile } \\
\text { strength, } \\
\text { ulti- } \\
\text { mate, } \\
\mathrm{MPa}\end{array}$ & $\begin{array}{c}\text { Tensile } \\
\text { strength, } \\
\text { yield, } \\
\mathrm{MPa}\end{array}$ & $\begin{array}{c}\text { Elonga- } \\
\text { tion at } \\
\text { break, } \\
\%\end{array}$ & $\begin{array}{c}\text { Modu- } \\
\text { lus of } \\
\text { elastic- } \\
\text { ity, GPa }\end{array}$ \\
\hline $\begin{array}{c}\text { DC-01 } \\
(1.0330)\end{array}$ & 280 & 160 & 28 & 201 \\
\hline
\end{tabular}

The experimental setup is shown in Fig. 2. The experiments were carried out on a CNC milling machine "DECKEL MAHO DMU-35M" 1 with a "Sinumerik 810D/840D" controller and "ShopMill" software using tungsten carbide fluteless drills with diameters of $5.4 \mathrm{~mm}$ and $7.3 \mathrm{~mm}$. The friction contact area ratio (FCAR) and the friction angle the of the drills were $75 \%$ and $33^{\circ}$, respectively. High speed steel fluteless tappers of an M6×1.0 mm and M $8 \times 1.25 \mathrm{~mm}$ were used for tapping. It should be noted that the cross-sections of the working sections of the both

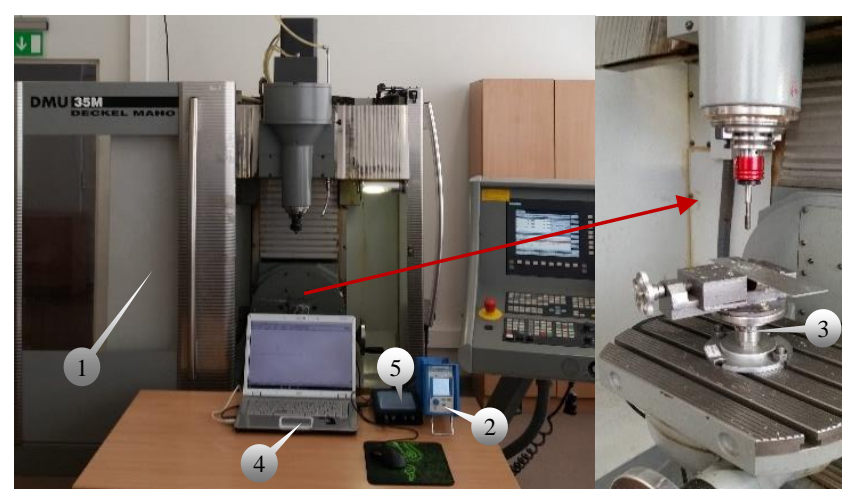

Fig. 2 Experimental setup of the friction drilling and tapping experiments: 1 - milling machine DMU-35 M; 2 - "Kistler" amplifier; 3 - "Kistler" force and torque sensor; 4 - computer; 5 - picoscope 
tools are polygonal shaped, in order to ensure better metal flow during the hole forming and tapping.

The axial force and torque were measured using a universal laboratory charge amplifier Kistler type 5018A 2 and a press force sensor Kistler type 9345B 3 mounted on the CNC table. Measuring ranges of the sensor: $-10 \ldots 10 \mathrm{kN}$ for force, $-25 \ldots .25 \mathrm{Nm}$ for torque; sensitivity: $\approx-3.7 \mathrm{pC} / \mathrm{N}$ for force, $\approx-200 \mathrm{pC} / \mathrm{Nm}$ for torque. The amplifier converts the charge signal from the piezoelectric pressure sensor into a proportional output voltage. The variation of the axial drilling force and torque was recorded to a computer 4 using a "PICOSCOPE 4424" oscilloscope 5 and "PicoScope 6" software.

The holes with 5.4 and $7.3 \mathrm{~mm}$ in diameter were formed in the sheets for further tapping of M6 and M8 threads.

\section{Results and discussion of the experimental investigation}

The results of the investigation of holes forming under different spindle speed and feed are presented in Figs. 3 - 6, of thread tapping ones - in Figs. 7 and 8.

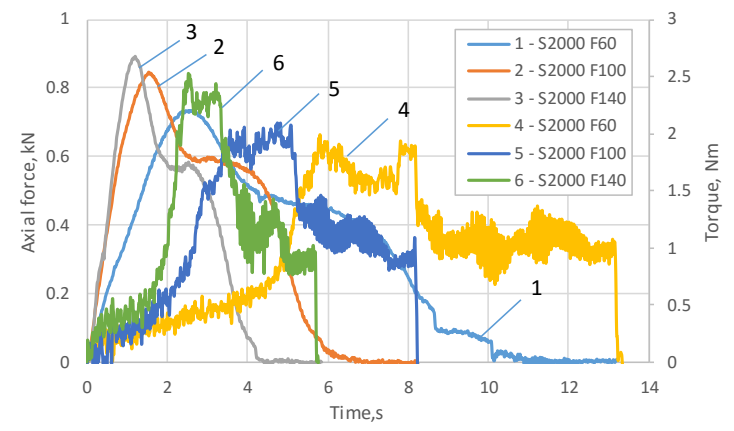

a

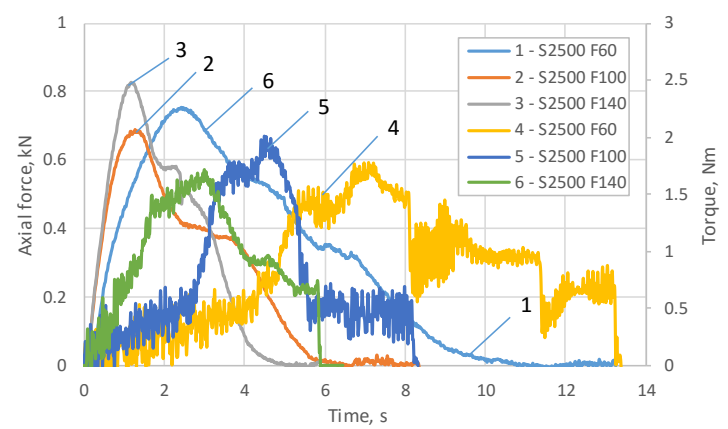

b

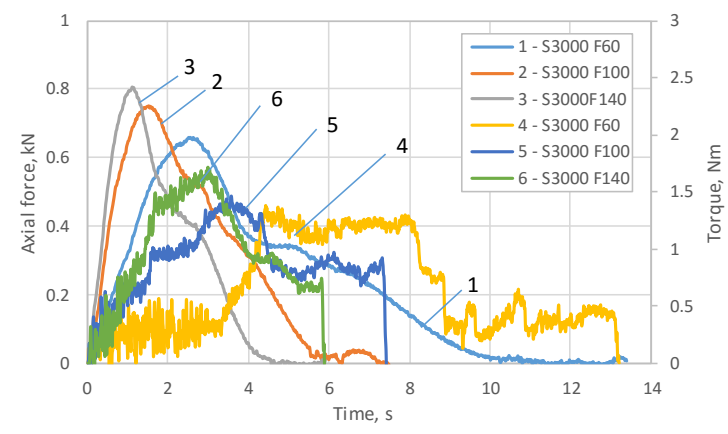

c

Fig. 3 Drilling force and torque variation during $5.4 \mathrm{~mm}$ hole forming on $1.0 \mathrm{~mm}$ sheet thickness: $\mathrm{a}-2000 \mathrm{rpm} ; \mathrm{b}-2500 \mathrm{rpm} ; \mathrm{c}-3000 \mathrm{rpm}$ ( 1 - 3 axial force; 4 - 6 torque)
Spindle speeds of 2000, 2500 and $3000 \mathrm{rpm}$ were used and for each of them three tool feed rates of 60,100 and $140 \mathrm{~mm} / \mathrm{min}$ were assigned in order to investigate the influence of these parameters on the axial hole forming and tapping forces as well as the torque along with a statistical prediction.

The matrix of the drilling and tapping experiments is presented in Table 2.

Table 2

Matrix of the drilling and tapping experiments

\begin{tabular}{|c|c|c|c|c|c|c|}
\hline \multirow[b]{2}{*}{ Material } & \multirow[b]{2}{*}{$\begin{array}{c}\text { Hole } \\
\text { diameter, } \\
\mathrm{mm}\end{array}$} & \multirow[b]{2}{*}{$\begin{array}{c}\text { Plate } \\
\text { thickness, } \\
\text { mm }\end{array}$} & \multicolumn{2}{|c|}{ Drilling } & \multicolumn{2}{|c|}{ Tapping } \\
\hline & & & \begin{tabular}{|c}
$\begin{array}{c}\text { Spindle } \\
\text { speed, } \\
\text { rpm }\end{array}$ \\
\end{tabular} & $\begin{array}{c}\text { Feed } \\
\text { rate, } \\
\mathrm{mm} / \mathrm{min}\end{array}$ & \begin{tabular}{|c|}
$\begin{array}{c}\text { Spindle } \\
\text { speed, } \\
\text { rpm }\end{array}$ \\
\end{tabular} & \begin{tabular}{|c}
$\begin{array}{c}\text { Feed } \\
\text { rate, } \\
\mathrm{mm} / \mathrm{rev}\end{array}$ \\
\end{tabular} \\
\hline \multirow{4}{*}{$\begin{array}{c}\text { Steel } \\
\text { DC-01 }\end{array}$} & \multirow{2}{*}{ M06-5.4 } & 1.0 & \multirow{4}{*}{$\begin{array}{l}2000 \\
2500 \\
3000\end{array}$} & \multirow{4}{*}{$\begin{array}{c}60 \\
100 \\
140\end{array}$} & \multirow{4}{*}{$\begin{array}{l}100 \\
200 \\
300\end{array}$} & \multirow{2}{*}{1.0} \\
\hline & & 1.5 & & & & \\
\hline & \multirow{2}{*}{ M08-7.3 } & 1.0 & & & & \\
\hline & & 1.5 & & & & 1.2. \\
\hline
\end{tabular}

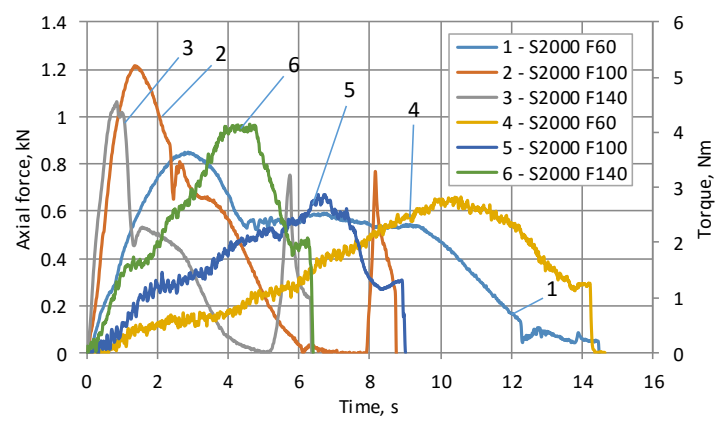

a

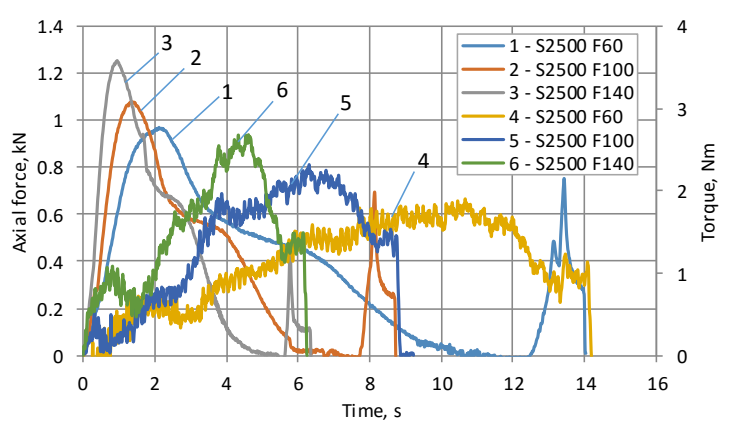

b

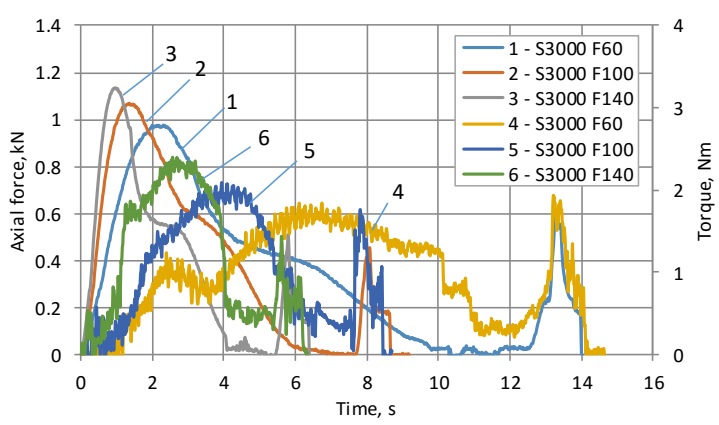

c

Fig. 4 Drilling force and torque variation during $5.4 \mathrm{~mm}$ hole forming on $1.5 \mathrm{~mm}$ sheet thickness: a - $2000 \mathrm{rpm} ; \mathrm{b}-2500 \mathrm{rpm}$; c - $3000 \mathrm{rpm}$ ( 1 - 3 axial force; 4 - 6 torque) 

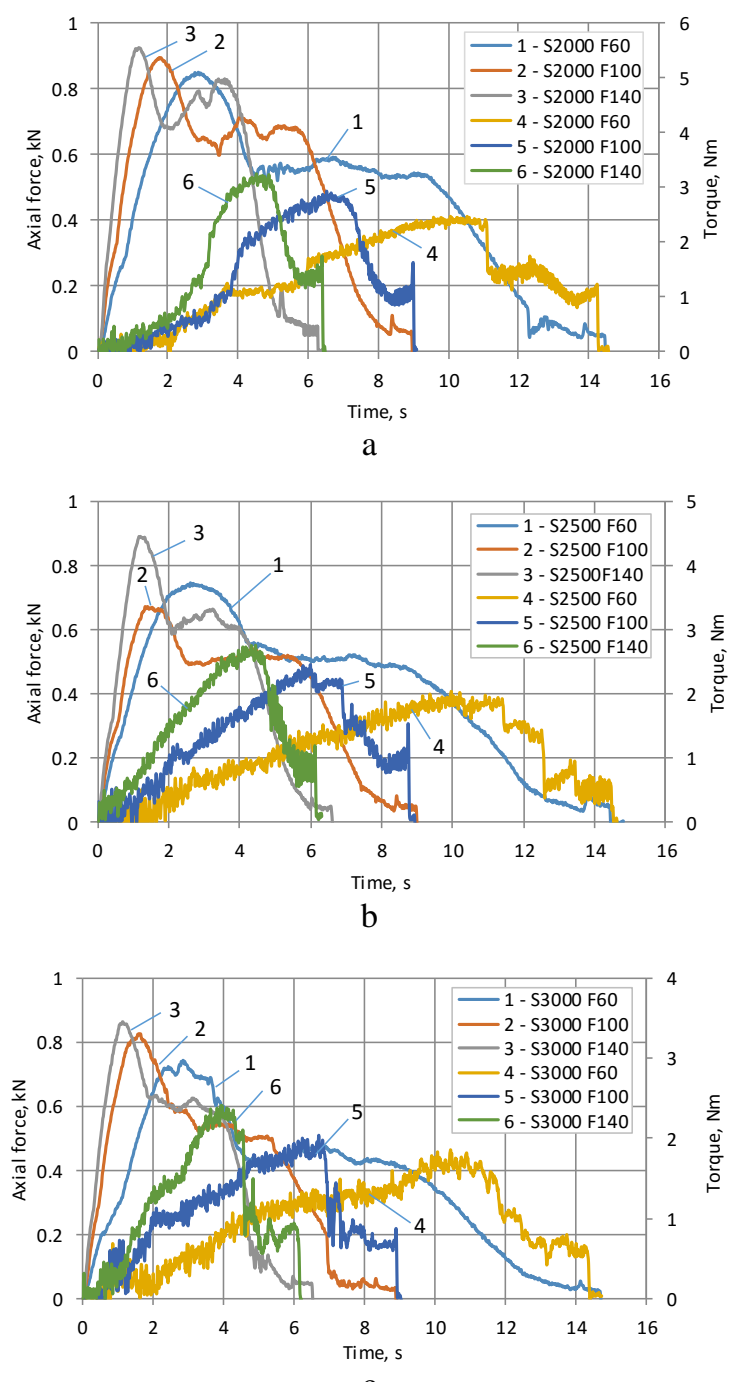

c

Fig. 5 Drilling force and torque variation during $7.3 \mathrm{~mm}$ hole forming on $1.0 \mathrm{~mm}$ sheet thickness: a $-2000 \mathrm{rpm} ; \mathrm{b}-2500 \mathrm{rpm}$; c - $3000 \mathrm{rpm}$ ( 1 - 3 axial force; 4 - 6 torque)

The experiment showed that the tool rotational speed has a significant influence on the axial force and torque variation. An analysis of the experimental results showed that the axial force, during the drilling process (from the initial contact until the end of the hole forming), varies in a very wide range. The axial force reaches its maximum value when the conical part of the tool fully penetrates into the plate. When the sheet is pierced, the axial force drastically decreases, meanwhile the torsion moment increases. The maximum torque is reached when the conical part of the tool is fully penetrated into the plate.

The experimental results enabled to conclude that the optimal machining data are spindle speed 2500-3000 rpm and forming feed rate $100 \mathrm{~mm} / \mathrm{min}$.

It was observed that the tapping force values are very low (less than $90 \mathrm{~N}$ ), therefore these results were not presented and discussed. The negative torque values during tapper withdrawal in Fig. 7 and 8 are not presented, because they are very low compared to the tapping torque. When the spindle speed is $2000 \mathrm{rpm}$, the maximum torque is obtained between 1 and $2 \mathrm{~s}$, after that it gradually decreases. The tapping torque was several times higher than the drilling torque.

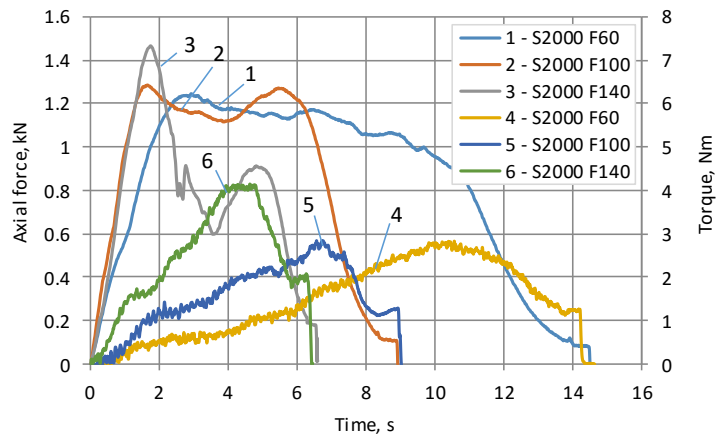

a

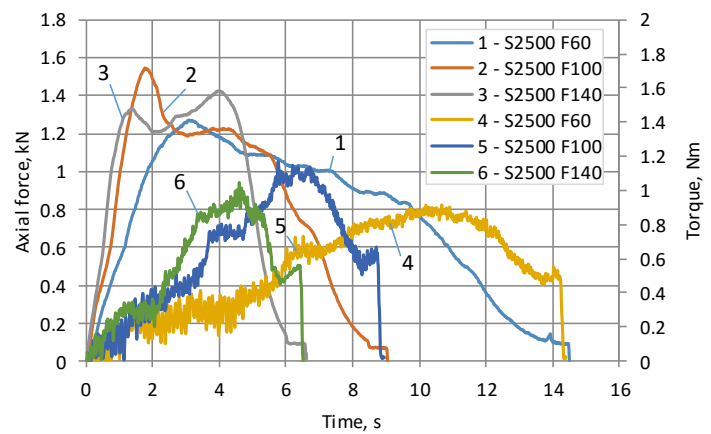

b

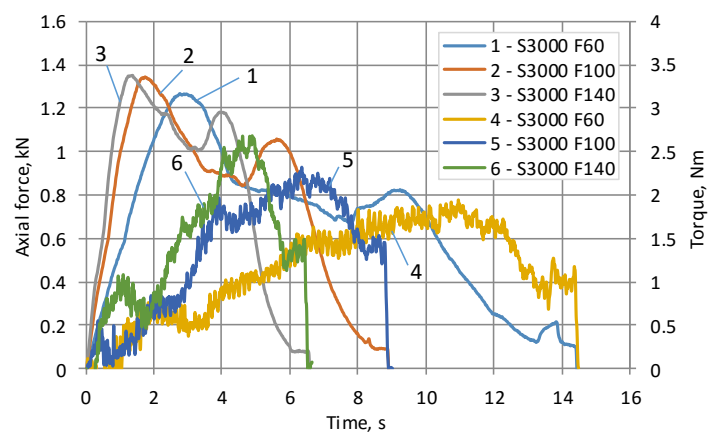

c

Fig. 6 Drilling force and torque variation during $7.3 \mathrm{~mm}$ hole forming on $1.5 \mathrm{~mm}$ sheet thickness: a $-2000 \mathrm{rpm} ; \mathrm{b}-2500 \mathrm{rpm} ; \mathrm{c}-3000 \mathrm{rpm}$ ( 1 - 3 axial force; 4 - 6 torque)

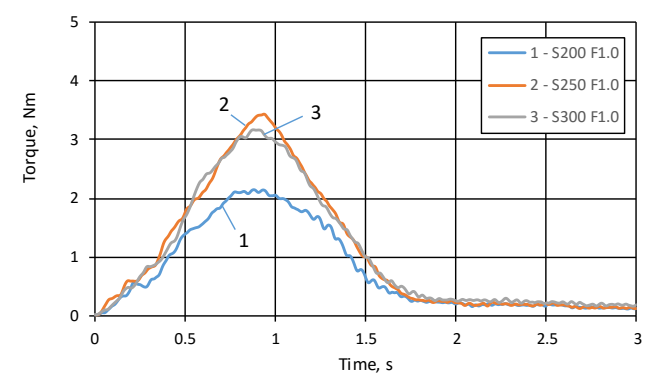

$\mathrm{a}$

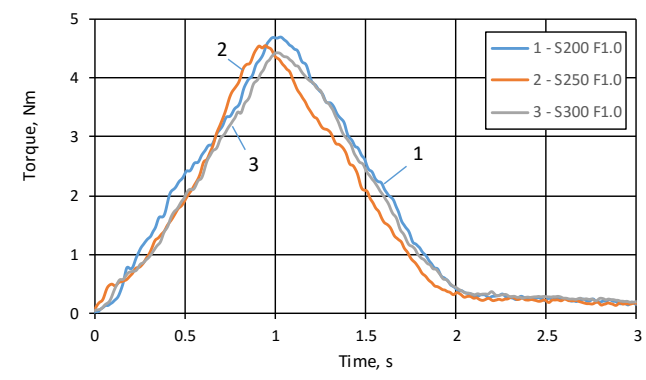

b

Fig. 7 Tapping torque variation during M6 thread forming: $\mathrm{a}-1.0 \mathrm{~mm}, \mathrm{~b}-1.5 \mathrm{~mm}$ sheet thickness 


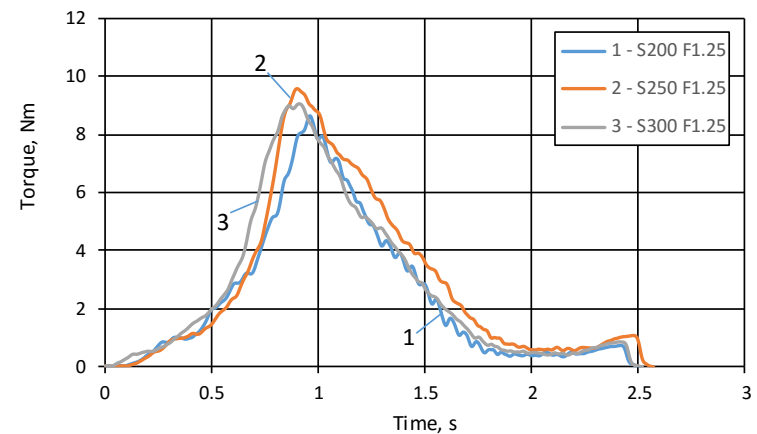

a

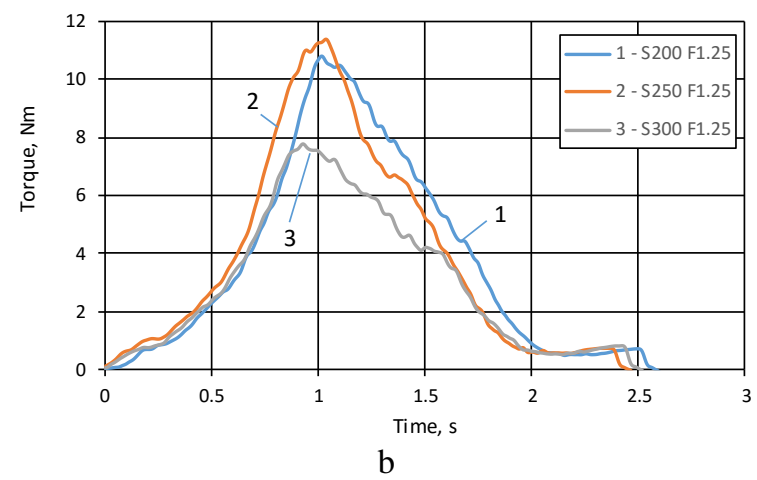

Fig. 8 Tapping torque variation during M8 thread forming: $\mathrm{a}-1.0 \mathrm{~mm}, \mathrm{~b}-1.5 \mathrm{~mm}$ sheet thickness

\section{Multivariable linear regression analysis}

The multivariable regression analysis was carried out in order to identify the influence of the drilling and tapping machining data on the maximum axial force $F_{\text {dmax }}$, maximum drilling and tapping torques $T_{\text {dmax }}, T_{\text {tmax }}$.

Experimental matrix, on which base regression analysis was performed, are presented in Tables 3 and 4.

It was assumed that the intervals of factors variation are tenuous, iterations can be limited by linear approximation

$$
Y=a_{0}+a_{1} X_{1}+a_{2} X_{2}+a_{3} X_{3}+\ldots+a_{n} X_{n},
$$

where $a_{0}, a_{1}, a_{2}, a_{3}, \ldots, a_{n}$ are unknown parameters of the model (regression coefficients); $n=1,2,3, \ldots, i$ are the factors of influence; $X_{1}, X_{2}, X_{3}, \ldots, X_{I}$ are independent variables.

Referring to this, a regression analysis was performed making presumption that the drilling force and the torque are stipulated as the entirety of drilling machining data, i.e. spindle rotational speed $S$, feed rate $F$, tool diameter $D$ and sheet thickness $t$ and could be expressed by a four variable regression model for $F_{d \max }, T_{d \max }$ and $T_{\max }$ respectively.

The summary output, analysis of variance, parameter values and comparative four variable linear regression analysis for maximal axial drilling force and torque and tapping torque are presented in Tables 5 and 6.

The regression model adequacy was evaluated taking into account the value of the correlation coefficient $R^{2}$ (Table 4). A high value of $R^{2}$ indicates that the obtained model adequately explains the variation of the forming parameters.
Table 3

Drilling force and torque regression matrix and results

\begin{tabular}{|c|c|c|c|c|c|c|c|}
\hline $\begin{array}{c}S, \\
\mathrm{rpm}\end{array}$ & $\begin{array}{c}F, \\
\mathrm{~mm} / \min \end{array}$ & $\begin{array}{c}D, \\
\mathrm{~mm}\end{array}$ & $\begin{array}{c}t, \\
\mathrm{~mm}\end{array}$ & $\begin{array}{c}F_{d \max }, \\
\mathrm{kN}\end{array}$ & $\begin{array}{c}F_{\text {dmax }}, \\
\mathrm{kN}\end{array}$ & $\begin{array}{c}T_{\text {dmax }}, \\
\mathrm{Nm}\end{array}$ & $\begin{array}{c}T_{\text {dmax }}, \\
\mathrm{Nm}\end{array}$ \\
\hline$X_{1}$ & $X_{2}$ & $X_{3}$ & $X_{4}$ & $Y_{\exp }$ & $Y_{\text {calc }}$ & $Y_{\exp }$ & $Y_{\text {calc }}$ \\
\hline \multirow{3}{*}{2000} & 140 & \multirow{3}{*}{5.4} & \multirow{3}{*}{1.0} & 0.88 & 0.82 & 2.40 & 2.58 \\
\hline & 100 & & & 0.84 & 0.75 & $\begin{array}{l}1.99 \\
\end{array}$ & 2.25 \\
\hline & 60 & & & 0.77 & 0.68 & 1.86 & 1.92 \\
\hline \multirow{3}{*}{2500} & 140 & \multirow{3}{*}{5.4} & \multirow{3}{*}{1.0} & 0.82 & 0.79 & 1.72 & 2.17 \\
\hline & 100 & & & 0.69 & 0.73 & 1.63 & 1.83 \\
\hline & 60 & & & 0.75 & 0.66 & 1.68 & 1.51 \\
\hline \multirow{3}{*}{3000} & 140 & \multirow{3}{*}{5.4} & \multirow{3}{*}{1.0} & 0.80 & 0.77 & 1.63 & 1.74 \\
\hline & 100 & & & 0.75 & 0.70 & 1.40 & 1.42 \\
\hline & 60 & & & 0.65 & 0.63 & 1.24 & 1.09 \\
\hline \multirow{3}{*}{2000} & 140 & \multirow{3}{*}{5.4} & \multirow{3}{*}{1.5} & 1.06 & 1.26 & 3.94 & 3.05 \\
\hline & 100 & & & 1.21 & 1.19 & 2.72 & 2.72 \\
\hline & 60 & & & 1.09 & 1.12 & 2.62 & 2.39 \\
\hline \multirow{3}{*}{2500} & 140 & \multirow{3}{*}{5.4} & \multirow{3}{*}{1.5} & 1.25 & 1.24 & 2.55 & 2.63 \\
\hline & 100 & & & 1.08 & 1.16 & 2.20 & 2.30 \\
\hline & 60 & & & 0.96 & 1.09 & 1.81 & 1.97 \\
\hline \multirow{3}{*}{3000} & 140 & \multirow{3}{*}{5.4} & \multirow{3}{*}{1.5} & 1.33 & 1.21 & 2.28 & 2.21 \\
\hline & 100 & & & 1.07 & 1.14 & 1.94 & 1.88 \\
\hline & 60 & & & 0.97 & 1.07 & 1.74 & 1.55 \\
\hline \multirow{3}{*}{2000} & 140 & \multirow{3}{*}{7.3} & \multirow{3}{*}{1.0} & 0.92 & 0.97 & 2.96 & 2.92 \\
\hline & 100 & & & 0.89 & 0.90 & 2.75 & 2.59 \\
\hline & 60 & & & 0.85 & 0.83 & 2.30 & 2.27 \\
\hline \multirow{3}{*}{2500} & 140 & \multirow{3}{*}{7.3} & \multirow{3}{*}{1.0} & 0.89 & 0.94 & 2.60 & 2.50 \\
\hline & 100 & & & 0.67 & 0.87 & 2.25 & 2.17 \\
\hline & 60 & & & 0.74 & 0.80 & 1.91 & 1.85 \\
\hline \multirow{3}{*}{3000} & 140 & \multirow{3}{*}{7.3} & & 0.86 & 0.92 & 2.28 & 2.08 \\
\hline & 100 & & 1.0 & 0.82 & 0.85 & 1.88 & 1.75 \\
\hline & 60 & & & 0.74 & 0.77 & 1.72 & 1.43 \\
\hline & 140 & & & 1.46 & 1.41 & 3.83 & 3.39 \\
\hline 2000 & 100 & 7.3 & 1.5 & 1.32 & 1.33 & 2.63 & 3.60 \\
\hline & 60 & & & 1.24 & 1.26 & 2.68 & 2.73 \\
\hline & 140 & & & 1.42 & 1.38 & 2.55 & 2.96 \\
\hline 2500 & 100 & 7.3 & 1.5 & 1.54 & 1.30 & 2.58 & 2.64 \\
\hline & 60 & & & 1.33 & 1.24 & 2.01 & 2.31 \\
\hline & 140 & & & 1.35 & 1.35 & 2.54 & 2.55 \\
\hline 3000 & 100 & 7.3 & 1.5 & 1.29 & 1.28 & 2.19 & 2.22 \\
\hline & 60 & & & 1.26 & 1.21 & 1.78 & 1.89 \\
\hline
\end{tabular}

Table 4

Thread tapping experiment matrix and regression results

\begin{tabular}{|c|c|c|c|c|c|}
\hline $\begin{array}{c}S, \\
\mathrm{rpm}\end{array}$ & $\begin{array}{c}F, \\
\mathrm{~mm} / \mathrm{min}\end{array}$ & $\begin{array}{c}D, \\
\mathrm{~mm}\end{array}$ & $\begin{array}{c}t, \\
\mathrm{~mm}\end{array}$ & $\begin{array}{c}T_{\text {tmax }}, \\
\mathrm{Nm}\end{array}$ & $\begin{array}{c}T_{\text {tmax }}, \\
\mathrm{Nm}\end{array}$ \\
\hline$X_{1}$ & $X_{2}$ & $X_{3}$ & $X_{4}$ & $Y_{\exp }$ & $Y_{\text {calc }}$ \\
\hline 200 & 1.0 & 6 & 1.0 & 2.13 & 3.08 \\
\hline 250 & 1.0 & 6 & 1.0 & 3.4 & 2.84 \\
\hline 300 & 1.0 & 6 & 1.0 & 3.12 & 2.60 \\
\hline 200 & 1.25 & 8 & 1.0 & 8.41 & 8.82 \\
\hline 250 & 1.25 & 8 & 1.0 & 9.57 & 8.58 \\
\hline 300 & 1.25 & 8 & 1.0 & 8.89 & 8.34 \\
\hline 200 & 1.0 & 6 & 1.5 & 4.65 & 4.39 \\
\hline 250 & 1.0 & 6 & 1.5 & 4.51 & 4.15 \\
\hline 300 & 1.0 & 6 & 1.5 & 4.41 & 3.91 \\
\hline 200 & 1.25 & 8 & 1.5 & 10.82 & 10.13 \\
\hline 250 & 1.25 & 8 & 1.5 & 11.31 & 9.89 \\
\hline 300 & 1.25 & 8 & 1.5 & 7.66 & 9.65 \\
\hline
\end{tabular}


As it is seen from Table 4, a good correlation between the experimental and the predicted values of $F_{\text {dmax }}$, $T_{d \max }$ and $T_{\text {tmax }}$ was observed. The analysis showed that the four variable linear regression model with $89 \%$ confidence for $F_{d \max }, 82 \%$ confidence for $T_{d \max }$ and $92 \%$ confidence for $T_{\text {tmax }}$ adequately evaluates the magnitude of the forming parameters.

Table 5 .

The results of the model validation are presented in

Table 5

Regression Statistics

\begin{tabular}{|l|c|c|c|}
\hline \multicolumn{1}{|c|}{ Regression data } & $F_{d \max }$ & $T_{d \max }$ & $T_{\text {tmax }}$ \\
\hline Multiple R & 0.94 & 0.90 & 0.96 \\
\hline R Square & 0.89 & 0.82 & 0.92 \\
\hline Adjusted R Square & 0.88 & 0.79 & 0.76 \\
\hline Standard Error & 0.09 & 0.27 & 1.08 \\
\hline Observations & 36 & 36 & 12 \\
\hline
\end{tabular}

The model significance was evaluated using the Fisher's statistical method. From the $F$-criteria tables [9], under the confidence interval $\alpha=0.05$, for drilling $F_{0.05}=2.69$ while for tapping $F_{0.05}=3.26$. Since the calculated $F$ value for drilling maximum force $F_{\text {calc }}=62.5 \gg$ $F_{0.05}=2.69$, for drilling torque $F_{\text {calc }}=34.2 \gg F_{0.05}=2.69$ and for tapping torque $F_{\text {calc }}=29.9>>F_{0.05}=3.26$, the model can be considered as significant and can be used for estimation of the axial force and torque.

Table 6

Analysis of variance (ANOVA)

\begin{tabular}{|l|c|c|c|}
\hline \multirow{2}{*}{} & \multicolumn{3}{|c|}{$d f$} \\
\cline { 2 - 4 } & $F_{d \max }$ & $T_{d \max }$ & $T_{\text {tmax }}$ \\
\hline Regression & 4 & 4 & 4 \\
\hline Residual & 31 & 31 & 8 \\
\hline Total & 35 & 35 & 12 \\
\hline$F$ & 62.5 & 34.2 & 29.9 \\
\hline
\end{tabular}

The coincidence of the experimental and calculated $F_{d \max }$ and $T_{d \max }$ values enabled to conclude that regression model Eq. (1) could be used to optimise friction drilling process for wide spectrum of the structural materials.

The significance of the regression analysis factors was estimated by normalising the factors using these expressions of normalised parameters.

$$
X_{i n}=\frac{2\left(X_{i}-X_{i 0}\right)}{\left(X_{i \max }+X_{i \min }\right)} \text { and } X_{i 0}=\frac{\left(X_{i \max }-X_{i \min }\right)}{2}
$$

where $i$ is the number of factor $X ; n$ is the row number for the each $X$ factor in the column.

The normalised regression coefficients (Table 7) showed that the thickness of the workpiece and the diameter of the tool have the highest influence on the axial drilling force; the tool diameter and the feed rate have the highest influence on the drilling torque, while the sheet thickness has the highest influence on the tapping torque.
Table 7

Normalised regression coefficients

\begin{tabular}{|c|c|c|c|}
\hline & \multicolumn{3}{|c|}{ Regression coefficients } \\
\hline & $F_{\text {dmax }}$ & $T_{\text {dmax }}$ & $T_{\text {tmax }}$ \\
\hline Intercept & -0.296 & 1.41 & -12.3 \\
\hline Variable $X_{1}$ & -0.131 & -2.09 & -1.21 \\
\hline Variable $X_{2}$ & 0.177 & 0.82 & 0 \\
\hline Variable $X_{3}$ & 0.486 & 1.12 & 20.9 \\
\hline Variable $X_{4}$ & 1.096 & 0.22 & 3.27 \\
\hline
\end{tabular}

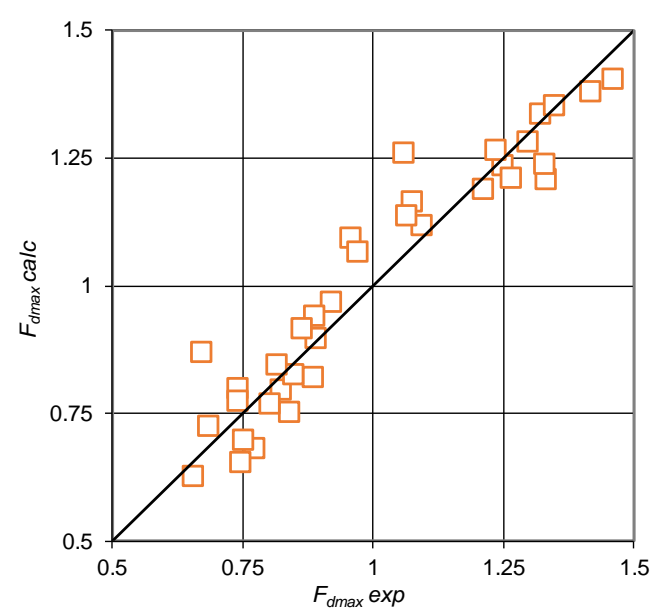

a

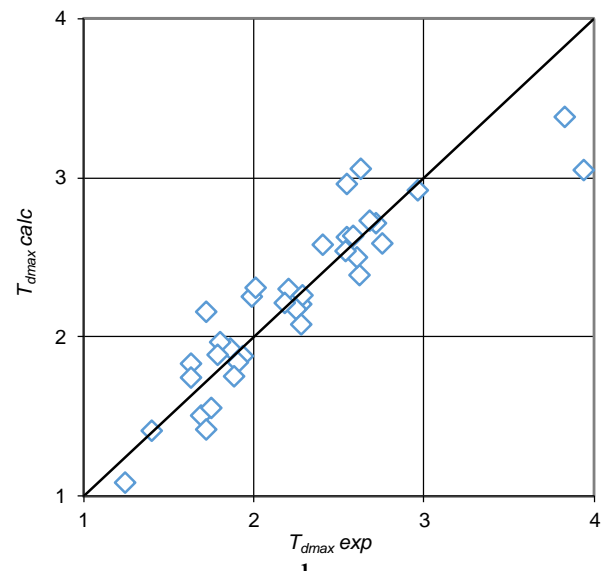

b

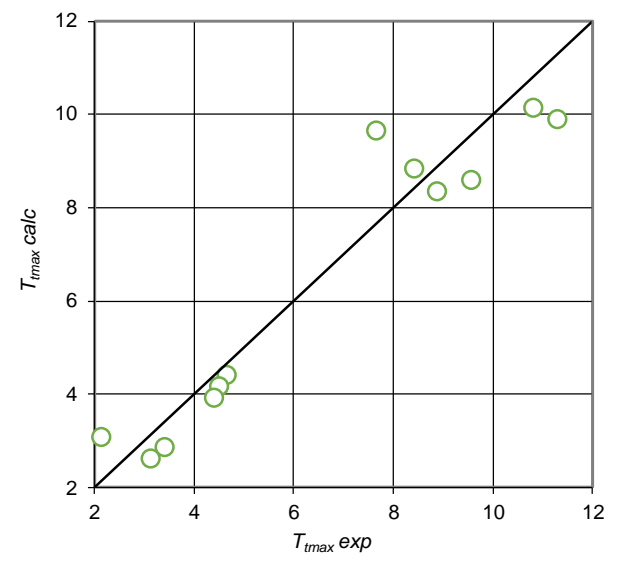

$c$

Fig. 9 Statistical evaluation of the holes forming and tapping results: $\mathrm{a}-$ drilling axial force; $\mathrm{b}$ - drilling torque; $\mathrm{c}$ - tapping torque 
The regression analysis of thread forming has showed that the feed rate during thread tapping has no influence, because the regression coefficient of this variable is 0 (Table 4). It means that the influence of the tapping parameters on the tapping torque can be approximated by the three variable regression model. The latter model was also verified and the regression statistics as well as the coefficients of the regression model were obtained the same as in the four variables regression.

\section{Conclusions}

An experimental analysis along with a multifactor regression analysis of holes and threads forming in thin plates were carried out and the axial force and torque variations were measured under different hole forming and tapping parameters.

The regression model adequacy was evaluated taking into account the value of the correlation coefficient $R^{2}$. A good correlation between the experimental and the predicted maximum values of axial force $F_{\text {dmax }}$, drilling torque $T_{d \max }$ and tapping torque $T_{t \max }$ was observed.

The regression analysis showed that the calculated $F$ value for drilling maximum force $F_{\text {calc }}=62.5 \gg F_{0.05}=$ 2.69 , for drilling torque $F_{\text {calc }}=34.2 \gg F_{0.05}=2.69$ and for tapping torque $F_{\text {calc }}=29.9 \gg F_{0.05}=3.26$, the model can be considered as significant and can be used for estimation of the axial force and torque.

The normalised regression coefficients showed that the thickness of the workpiece and the diameter of the tool have the highest significance on the axial drilling force; the most significant drilling parameter on the drilling torque is the tool diameter and feed rate, while the highest influence on tapping torque has the sheet thickness.

The research allows to predict optimal parameters for holes and treads forming in thin plates in order to optimise the drilling and tapping force along with the torque and, as a consequence, to decrease tool wear and extend the lifetime of the tools.

\section{References}

1. Miller, Scott F.; Peter J. Blau, and Albert J. Shih. 2007. Tool wear in friction drilling, International Journal of Machine Tools and Manufacture 47(10): 1636-1645. http://dx.doi.org/10.1016/j.ijmachtools.2006.10.009.

2. Ku, W.L.; Hung, C.L.; Lee, S.M.; Chow, H.M. 2011. Optimization in thermal friction drilling for SUS 304 stainless steel, The International Journal of Advanced Manufacturing Technology 53(9-12): 935-944. http://dx.doi.org/10.1007/s00170-010-2899-5.

3. Nathan, S.R.; Malarvizhi, S.; Balasubramanian, V.; Rao, A.G. 2016. Failure analysis of tungsten based tool materials used in friction stir welding of high strength low alloy steels, Engineering Failure Analysis 66: 8898.

http://dx.doi.org/10.1016/j.engfailanal.2016.04.018.

4. Chow, H.M.; Lee, S.M.; Yang, L.D. 2008. Machining characteristic study of friction drilling on AISI 304 stainless steel, Journal of Materials Processing Technology 207(1-3): 180-186. http://dx.doi.org/10.1016/j.jmatprotec.2007.12.064.

5. Lee, S. M.; Chow, H.M.; Yan, B.H. 2007. Friction drilling of IN-713LC cast superalloy, Materials and Manufacturing Processes 22(7-8): 893-897. http://dx.doi.org/10.1080/10426910701451697.

6. Lee, S.M.; Chow, H.M.; Huang, F.Y.; Yan, B.H. 2008. Friction drilling of austenitic stainless steel by uncoated and PVD AlCrN- and TiAlN-coated tungsten carbide tools, International Journal of Machine Tools and Manufacture 49(1): 81-88. http://dx.doi.org/10.1016/j.ijmachtools.2008.07.012.

7. Miller, Scott F.; Jia Tao; Albert J. Shih. 2006. Friction drilling of cast metals, International Journal of Machine Tools and Manufacture 46(12): 1526-1535. http://dx.doi.org/10.1016/j.ijmachtools.2005.09.003.

8. de Carvalho, A.O.; Brandão, L.C.; Panzera, T.H.; Lauro, C.H. 2012. Analysis of form threads using fluteless taps in cast magnesium alloy (A5.4 MM0), Journal of Materials Processing Technology 212(8): 1753-1760. http://dx.doi.org/10.1016/j.jmatprotec.2012.03.018.

9. Hines, W.W.; Montgomery, D.C. 1990. Probability and statistics in engineering and managements science. $-3^{\text {rd }}$ ed. Wiley, N.Y.

P. Krasauskas, S. Kilikevičius, R. Česnavičius, R. Dundulis

\section{STATISTICAL RESEARCH ON FORMING OF THREADED HOLES IN THIN PLATES}

S u m m a r y

This paper presents an investigation of the influence of machining data and workpiece thickness on drilling forces and moments during holes and treads forming in thin plates along with a multifactor linear regression analysis of the results. The research allows to predict optimal parameters for holes and treads forming in thin plates in order to optimise the drilling and tapping force along with the torque and, as a consequence, to decrease tool wear and extend the lifetime of the tools.

Keywords: friction drilling, fluteless tapping, thin plate, regression analysis.

Received April 20, 2016 Accepted May 31, 2016 